\title{
Effect of Cross-Training on Physical Fitness and Performance in Physically Disabled Crawl Swimmers.
}

\section{Tarek Mahdy Atiya}

Assistant Professor, Faculty of Physical Education for Boys, Zagazig University, Egypt.

\begin{abstract}
This research aims to identify the effect of cross-training on development of some physical fitness parameters performance of physically disabled crawl swimmers. Ten disabled swimmers from Al-Salam Sport Club team in Banha city, were recruited to participate in the study. Subjects were tested for, Pull up on horizontal bar, $3 \mathrm{Kg}$ medical ball push, Trunk flexibility, post-50 swim Blood lactate concentration $50 \mathrm{~m} \mathrm{Crawl}$ and Stroke Strength. Results: significant improvements was observed for (name all fitness attributes that showed improvements) after the training period. Cross training seems to be an effective way to improve certain physical fitness attributes as well as performance level in disabled swimmers .
\end{abstract}

Key words: Cross-training - Physically disabled-Crawl swimmers.

\section{Introduction :}

$\mathrm{E}$ xercises to improve maximal muscle strength and maximal aerobic endurance capacity are considered essential elements for enhancing competitive swimming performance. Several studies have investigated the effects of maximal strength or strength-related training (Girold et al., 2006; 2007; Miyashita and Kanehisa, 1983; Petersen et al., 1984; Sharp et al., 1982; Tanaka et al., 1993; Toussaint and Vervoorn, 1990; Trappe and Pearson, 1994) or aerobic endurance capacity training (Barzdukas et al., 1992; Costill et al., 1988; 1991, D'Acquisto et al. 1992; Faude et al. 2008; Gergley et al. 1984), but to the best of our knowledge none have investigated a combined intervention in modern swimming. Former studies have found positive effects of interventions combining strength and endurance training for both basketball (Balabinis et al. 2003) and soccer athletes (Hoff et al. 2002), along with runners (Tanaka et al. 1998; Yamamoto et al. 2008) and cyclists (Tanaka et al. 1998). The strength training approach is neural adaptations, simultaneously limiting muscular hypertrophy and increasing body weight (Sale 2003)

Strength training in swimming has been found to improve swimming performance (Girold et al. 2007, Toussaint and Vervoorn 1990; Trappe and Pearson 1994) and performance- related parameters such as increased stroke length (Toussaint and Vervoorn 1990), reduced stroke rate (Girold et al. 2007) and increased tethered swimming force (Girold et al. 2007, Toussaint and Vervoorn 1990; Trappe and Pearson 1994). Swimming velocity is the product of stroke length and stroke rate.

However, of the three studies investigating the effects of dry land strength training in swimmers (Tanaka et al., 1993; Trappe and Pearson, 1994; Girold et al., 2007) only one 
found benefits of a combined strength and swim training group versus a swim-training alone (Girold et al., 2007). Several studies, including dry land training protocols, reported positive effects on sprint performances in swimming, and generally the gains in sprint performance are consistent: between 1.3 and $4.4 \%$ (Costill, 1999; Pichon et al., 1995; Strass, 1988). Strass (1988) showed that a maximal strength program using free weights led to a significant 4.4 and $2.1 \%$ increase in performance over 25 and $50 \mathrm{~m}$ freestyle, respectively. Interestingly, althouth popular among disabled persons, data about swimrelated parameters and their response to . specific training regimens are scarce. On the other hand, Many studies have been done on the importance of physical activity and active lifestyle both for the general public as well as some kind of disability (Butter L and Anderson S. 2002.)

When observing the swimming stroke mechanics of persons with permanent physical disabilities it is apparent that the anatomic and neuromuscular deficits that are present have resulted in the evolution of unique movement patterns in the water (Daly \& Vanlandewijck, 1999; Prins 1988)

The traditional approach to swimming instruction for persons with permanent physical disabilities has been to modify the standard teaching methods used with ablebodied persons. The expectation is that, in spite of the limited strength and neuromuscular coordination, adequate skills will be acquired provided adequate time is devoted to the activity. This approach although practically sound, can be improved by increasing our knowledge of the potential and limitations for movement in the water as exhibited by individuals with varied physical disabilities (Dunlap 1997; Dummer 1999;
Prins, 1988; Wu \& Williams, 1999). However, it is of particular interest to gain informations about effects of strength training regimens in this specific population of swimmers. Therefore, the aim of this research is to identify the effect of crosstraining on development of some physical variables on muscle fatigue and achievement level for physically disabled crawl swimmers.

\section{Procedures:}

\section{The research sample:}

The researcher utilized the experimental approach, the pre and post design for one group, with (10) disabilities swimmers from Al-Salam Sport Club team in Banha city, who were selected by deliberate way. They were tested for Pull up on horizontal bar, 3 $\mathrm{Kg}$ medical ball push, Trunk flexibility, Blood lactate before effort, Blood lactate after effort, $50 \mathrm{~m}$ Crawl and Stroke Strength .

\section{Tools and equipment of collecting data:}

Physical tests of pull up on horizontal bar, 3 $\mathrm{Kg}$ medical ball push and Trunk flexibility, Measure of blood lactate before and after effort, measure of $50 \mathrm{~m}$ crawl and stroke strength by dynamometer .

The researcher performed the pre-measures on 11/05/2012 till 14/05/2012. Started $16 / 05 / 2012$ for a period of (10) weeks at the rate of (3) sessions per week and until 24/07/2012. 25/07/2012 till 28/07/2012 the researcher performed the post measures.

Experimental procedures: training regimens should be elaborated in details here, how many strength training sessions were conducted, for how many years, what was the number of sets, repetitions, order of exercises....? this is one of the biggest issues in the paper and should be presented clearly! 
Training sessions contains (order of exercises) weights Training, Plyometric Training, ballistic training, training in deep water, sand running and team sports, for 3 sets and 10 repetitions for each .

\section{Results and discussion:}

Table 1:

Difference Significance for Pre and Post Measures for Experimental Group in Physical Variables $\mathbf{N}=10$

\begin{tabular}{|c|c|c|c|c|c|c|}
\hline \multirow{2}{*}{ Variables } & \multirow{2}{*}{ Unit } & \multicolumn{2}{|c|}{ Pre } & \multicolumn{2}{|c|}{ Post } & \multirow{2}{*}{ T- stat } \\
\hline & & Mean & Variance & Mean & Variance & \\
\hline Pull up on horizontal bar & No. & 10.00 & 2.62 & 15.60 & 2.49 & $4.17 *$ \\
\hline 3 Kg medical ball push & Metre & 4.75 & 0.49 & 5.90 & 0.35 & $5.53 *$ \\
\hline Trunk flexibility & $\mathrm{Cm}$ & 6.50 & 2.28 & 10.00 & 1.92 & $3.95 *$ \\
\hline
\end{tabular}

* Significantly different at $\mathbf{p}<.05=2.262$

Table 2:

Rate of Improvement for Post Measures for Experimental Group in Physical Variables $\mathbf{N}=10$

\begin{tabular}{|c|c|c|c|c|}
\hline Variables & Unit & Pre & Post & $\begin{array}{c}\text { Rate of } \\
\text { Improvement }\end{array}$ \\
\hline Pull up on horizontal bar & No. & 10.00 & 15.60 & $56.00 \%$ \\
\hline 3 Kg medical ball push & Metre & 4.75 & $\mathbf{5 . 9 0}$ & $\mathbf{2 4 . 2 1 \%}$ \\
\hline Trunk flexibility & Cm & $\mathbf{6 . 5 0}$ & $\mathbf{1 0 . 0 0}$ & $\mathbf{5 3 . 8 5 \%}$ \\
\hline
\end{tabular}

Table 3:

Difference Significance for Pre and Post Measures for Experimental Group in Functional Variables $\mathbf{N}=\mathbf{1 0}$

\begin{tabular}{|c|c|c|c|c|c|c|}
\hline \multirow{2}{*}{ Variables } & \multirow{2}{*}{ Unit } & \multicolumn{2}{|c|}{ Pre } & \multicolumn{2}{|c|}{ Post } & \multirow{2}{*}{ T-stat } \\
\hline & & Mean & Variance & Mean & Variance & \\
\hline Blood lactate before effort & mgldl & 10.27 & 0.64 & 9.61 & 0.49 & 2.81* \\
\hline Blood lactate after effort & mgldl & 64.12 & 7.31 & 55.33 & 4.82 & $3.25 *$ \\
\hline
\end{tabular}

* Significantly different at $\mathbf{p}<.05=2.262$ 
Table 4:

Rate of Improvement for Post Measures for Experimental Group in Functional Variables $\mathrm{N}=10$

\begin{tabular}{|c|c|c|c|c|}
\hline Variables & Unit & Pre & Post & $\begin{array}{c}\text { Rate of } \\
\text { Improvement }\end{array}$ \\
\hline Blood lactate before effort & mgldl & 10.27 & 9.61 & $6.87 \%$ \\
\hline Blood lactate after effort & mgldl & 64.12 & 55.33 & $15.89 \%$ \\
\hline
\end{tabular}

Table 5:

Difference Significance for Pre and Post Measures for Experimental Group in 50 m Crawl \& Stroke Strength $\quad \mathbf{N}=\mathbf{1 0}$

\begin{tabular}{|c|c|c|c|c|c|c|}
\hline \multirow{2}{*}{ Variables } & \multirow{2}{*}{ Unit } & \multicolumn{2}{|c|}{ Pre } & \multicolumn{2}{|c|}{ Post } & \multirow{2}{*}{ T- stat } \\
\hline & & Mean & Variance & Mean & Variance & \\
\hline $50 \mathrm{~m}$ Crawl & Second & 45.72 & 0.98 & 44.61 & 0.91 & $2.68 *$ \\
\hline Stroke Strength & Kg & 13.25 & 2.11 & 15.80 & 1.69 & $2.94 *$ \\
\hline
\end{tabular}

* Significantly different at $\mathbf{p}<.05=2.262$

Table 6:

Rate of Improvement for Post Measures for Experimental Group in 50 m Crawl \& Stroke Strength $\mathbf{N}=10$

\begin{tabular}{|c|c|c|c|c|}
\hline Variables & Unit & Pre & Post & $\begin{array}{c}\text { Rate of } \\
\text { Improvement }\end{array}$ \\
\hline 50 m Crawl & Second & 45.72 & 44.61 & $2.49 \%$ \\
\hline Stroke Strength & Kg & 13.25 & 15.80 & $19.25 \%$ \\
\hline
\end{tabular}

Table (1) shows significant statistical differences at the level of 0.05 between the two measures pre and post of physical variables (arms strength \& power and Trunk flexibility) in favour of the post measuring to the pre measuring.

Table (2) shows rate of improvement for physical variables (arms strength \& power and Trunk flexibility) for post measurement.

Improvement in physical variables (arms strength \& power and Trunk flexibility) as a result of cross training program which contents of weight training for arms and trunk with playing basketball (as a first stage), second stage of the training program contents of high intensity of plypmetric training, third stage contents of ballistic training with practicing volleyball, this results in on line with (Stian Aspenes, 2009) that cross training has an effected way in improvement of physical abilities in athletes.

Table (3), (4) show significant statistical differences at the level of 0.05 between the two measures pre and post of functional variables (blood lactic before and after effort) and rate of improvement for functional variables in favour of the post measuring to the pre measuring.

The researcher attributes the result of improvement in level of $400 \mathrm{~m}$ cra functional variables to adaptation due to cross training 
program, which allows swimmer to get of blood lactic.

This result is on line with (Kenneth, 2003) that training process led to enhance blood lactic concentrations which reduces fatigue phase in swimmers.

Table (5), (6) show significant statistical differences at the level of 0.05 between the two measures pre and post of $50 \mathrm{~m} \mathrm{Crawl}$ and Stroke Strength and rate of improvement for $50 \mathrm{~m} \mathrm{Crawl}$ and Stroke Strength in favour of the post measuring to the pre measuring.

This result is on line with (Girold et al. 2007, Toussaint and Vervoorn 1990; Trappe and Pearson 1994) that strength training in swimming improves swimming performance and performance- related parameters such as increased stroke length. (Toussaint and Vervoorn 1990), reduced stroke rate (Girold et al. 2007) and increased tethered swimming force (Girold et al. 2007, Toussaint and Vervoorn 1990; Trappe and Pearson 1994). Cross training improves physical abilities of endurance, strength, power, agility and flexibility, and improves physiological responds of sport performance.

\section{References:}

1. Barzdukas, A., Franciosi, P., Trappe, S., Letner, C. and Troup, J.P. (1992) Adaptations to interval training at common intensities and different work: Rest ratios. In: Biomechanics and Medicine in Swimming VI. Eds: Maclaren, D., Reilly, T. \& Lees, A. Cambridge, E \& FN Spon. 189-194.

2. Balabinis, C.P., Psarakis, C.H., Moukas, M., Vassiliou, M.P. and Behrakis, P.K. (2003) Early phase changes by concurrent endurance and strength training. Journal of Strength and Conditioning Research 17, 393-401.

3. Butter L and Anderson S. (2002): Inspiring students to a lifetime of physical activity, the journal of physical education, recreation $\&$ dance, 73: 21-25.
4. Costill, D.L., Flynn, M.G., Kirwan, J.P., Houmard, J.A., Mitchell, J.B., Thomas, R. and Park, S.H. (1988) Effects of repeated days of intensified training on muscle glycogen and swimming performance. Medicine and Science in Sports and Exercise 20, 249-254.

5. Daly, D. J., \& Vanlandewijck, Y. (1999). Some criteria for evaluating swimming classification. Adapted Physical Activity Quarterly, 16, 271-289.

6. D'Acquisto, L.J., Barzdukas, A., Dursthoff, P., Letner, C. and Troup, J.P. (1992) Physiological adaptations to 60 vs 20 minutes of swim training at 76\% VO2max. In: Biomechanics and Medicine in Swimming VI. Eds: Maclaren, D., Reilly, T. \& Lees, A. Cambridge, E \& FN Spon. 195-199.

7. Dummer, G. M. (1999). Classification of swimmers with physical disabilities. Adapted Physical Activity Quarterly, 16, 216-218.

8. Dunlap E. "Swim stroke training and modification for rehabilitation." In: Ruoti RG, Morris DM, Cole AJ (eds). Aquatic Rehabilitation for Health Professionals. JB Lippincott Co: Philadelphia, PA; 1997:

9. Faude, O., Meyer, T., Scharhag, J., Weins, F., Urhausen, A. And Kindermann, W. (2008) Volume vs. intensity in the training of competitive swimmers. International Journal of Sports Medicine 29, 906-912.

10. Gergley, T.J., McArdle, W.D., DeJesus, P., Toner, M.M., Jacobowitz, S. and Spina, R.J. (1984) Specificity of arm training on aerobic power during swimming and running. Medicine and Science in Sports and Exercise 16, 349-354.

11. Girold, S., Maurin, D., Dugue, B., Chatard, J.C. and Millet, G. (2007) Effects of dry-land vs. Resisted- and assisted-sprint exercises on swimming sprint performances. Journal of Strength and Conditioning Research 21, 599-605.

12. Girold, S., Calmels, P., Maurin, D., Milhau, N. and Chatard, J.C. (2006) Assisted and resisted sprint training in swimming. Journal of Strength and Conditioning Research 20, 547-554.

13. Hoff, J., Gran, A. and Helgerud, J. (2002a) Maximal strength training improves aerobic endurance performance. Scandinavian Journal of Medicine and Science in Sports 12, 288-295.

14. Kenneth (2003): Upper Body Exercise Capaise in With Spinabifida, Adapted Physical Activity, 15. 
15. Miyashita, M. and Kanehisa, H. (1983) Effects of isokinetic, isotonic and swim training on swimming performance. In: Biomechanics and Medicine in Swimming IV. Eds: Hollander, A. P., Huijing, P.A. \& De Groot, G. Champaign, Illinois, Human Kinetics Publishers. 329-334.

16. Pichon, F., Chatard, J.C., Martin, A. and Cometti, G. (1995) Electrical stimulation and swimming performance. Medicine and Science in Sports and Exercise 27, 1671-1676.

17. Petersen, S.R., Miller, G.D., Wenger, H.A. and Quinney, H.A. (1984) The acquisition of muscular strength: The influence of training velocity and initial vo2 max. Canadian Journal of Applied Sport Sciences 9, 176-180.

18. Prins, J. H. (1988). An analysis of basic swimming techniques with implications for designing rehabilitative and instructional programs for the physically disabled. U.S. Department of Education. Washington D.C., National Institute for Disability \& Rehabilitation Research, Office of Special Education and Rehabilitation Services, (Grant No. H133C8002888).

19. Sale, D.G. (2003) Neural adaptation to strength training. In: Strength and power in sport. Ed: Komi, P. V. Second edition. Oxford, Blackwell Publishing. 281-314.

20. Sharp, R.L., Troup, J.P. and Costill, D.L. (1982) Relationship between power and sprint freestyle swimming. Medicine and Science in Sports and Exercise 14, 53-56.

21. Strass, D. (1988) Effects of maximal strength training on sprint performance of competitive swimmers. In: Swimming Science V. Eds: Ungerechts, B.E., Wilke, K. and Reischle, K. Spon Press, London. 149-156.

22. Stian Aspenes, Per-Ludvik Kjendlie, Jan Hoff and Jan Helgerud (2009): Combined strength and endurance training in competitive swimmers, CJournal of Sports Science and Medicine, 8, 357365.

23. Tanaka, H., Costill, D., Thomas, R., Fink, W.J. and Widrick, J.J. (1998) Impact of resistance training on endurance performance. A new form of cross-training? Sports Medicine 25, 191-200.

24. Tanaka, H., Costill, D.L., Thomas, R., Fink, W.J. and Widrick, J.J. (1993) Dry-land resistance training for competitive swimming. Medicine and Science in Sports and Exercise 25, 952-959.

25. Toussaint, H.M. and Vervoorn, K. (1990) Effects of specific high resistance training in the water on competitive swimmers. International Journal of Sports Medicine 11, 228-233.

26. Trappe, S. and Pearson D.R. (1994) Effects of weigth assisted dry-land strength training on swimming performance. Journal of Strength and Conditioning Research 8, 209-213.

27. Wu, S. K., \& Williams, T., (1999). Swimming, impairment, and classification. Adapted Physical Activity Quarterly, 16, 251-270.

28. Yamamoto, L.M., Lopez, R.M., Klau, J.F., Casa, D.J., Kraemer, W.J. and Maresh, C.M. (2008) The effects of resistance training on endurance distance running performance among highly trained runners: A systematic review. Journal of Strength and Conditioning Research 22, 2036-2044. 
